\title{
Altered Golgi apparatus in hydrostatically loaded articular cartilage chondrocytes
}

\author{
Jyrki J Parkkinen, Mikko J Lammi, Alpo Pelttari, Heikki J Helminen, Markku Tammi, \\ Ismo Virtanen
}

\begin{abstract}
Objectives Articular cartilage proteoglycan content is controlled by joint loading. This study aimed to elucidate the role of hydrostatic pressure in this regulation.

Methods Primary cultures of chondrocytes from bovine articular cartilage, grown on coverslips, were subjected to 5 , 15 , or $30 \mathrm{MPa}$ hydrostatic pressure, applied continuously or cyclically at $0 \cdot 125$ or $0.05 \mathrm{~Hz}$. The Golgi apparatus was visualised either by a fluorochrome coupled wheat germ agglutinin or by transmission electron microscopy. Proteoglycan synthesis was studied by the incorporation of sulphur-35 labelled sulphate.
\end{abstract}

Results After $30 \mathrm{MPa}$ continuous hydrostatic pressure, the Golgi apparatus was observed in a compact form with a concomitant decrease in proteoglycan synthesis. The normal stacked appearance of the Golgi apparatus was no more visible in the electron microscopy preparation of the pressurised chondrocytes. This effect was reversible and was also noticed after $15 \mathrm{MPa}$ continuous load, though to a minor extent. Cyclic pressures (5-30 MPa) caused no apparent change in the Golgi apparatus. The shape of some cells changed to a more retracted form after 30 MPa continuous pressure. Nocodazole, which causes disassembly of the microtubules, blocked the compacting influence of pressurisation on the Golgi apparatus, and reduced proteoglycan synthesis to about half of the control level. Conclusions The packing of the Golgi apparatus is dependent on microtubules and may contribute to the inhibition of proteoglycan synthesis observed in articular cartilage subjected to high hydrostatic pressure.

(Ann Rheum Dis 1993; 52: 192-198)

Microscopy,

University of Kuopio,

PO Box 1627, SF-70211

Kuopio, Finland

A Pelttari

Department of

Anatomy, University of Helsinki,

Siltavuorenpenger 20, 00170 Helsinki, Finland

I Virtanen

Correspondence to: Dr Parkkinen.

Accepted for publication 28 October 1992 glycosaminoglycan content of articular cartilage, ${ }^{23}$ whereas strenuous exercise has an opposite influence with proteoglycans reduced, particularly from the superficial zone. ${ }^{4}$ Lack of load bearing results in a reduced proteoglycan content in cartilage. ${ }^{56}$ The changes in proteoglycan content lead to alterations in the biomechanical properties of cartilage. ${ }^{7}$ The atrophy following reduced loading and the loss of superficial zone proteoglycans following strenuous exercise may put articular cartilage at risk of permanent injury.

During joint loading chondrocytes in articular cartilage are first exposed to a hydrostatic pressure gradient which is followed by deformation and fluid flow. The latter events are associated with streaming currents and physicochemical changes in the extracellular tissue matrix. Of these factors only hydrostatic pressure can be investigated independently, because it can be applied on cells and tissues without simultaneous fluid flow or tissue deformation. When applied experimentally, its action is uniform in all parts of the tissue. The most striking effects of hydrostatic pressure are exerted on sites of phase changes such as the water/lipid interphase in membranes. ${ }^{8}$ Hydrostatic pressure has been suggested to control protein and proteoglycan synthesis in articular cartilage. ${ }^{9} 10$

Hydrostatic pressure has multiple effects on cellular processes. ${ }^{8}$ Most studies, however, have been performed on single cell organisms and few data are available on the effects of hydrostatic pressure on mammalian cells. Relatively small pressures ( $5 \mathrm{MPa}$ ) stimulate Na-K ATPase activity in erythrocytes, ${ }^{11}$ but higher pressures have inhibitory effects, e.g. on exocytosis ${ }^{12}$ and protein synthesis. ${ }^{13}$ Malignant cells may be more resistant to hydrostatic pressure than normal cells. ${ }^{14}$

The Golgi apparatus of the mammalian cell is an organelle which consists of an interconnected network of stacks of flattened cisternae and tubular structures. ${ }^{15}$ The Golgi apparatus is localised in a juxtanuclear position together with the microtubule organising centre. Intact interphase microtubules are essential in maintaining the structural integrity and location of the Golgi apparatus as shown experimentally by the aid of microtubule disrupting agents, such as colchicine, nocodazole, and vinca alkaloids. ${ }^{15} 16$ In cells treated with these agents, the Golgi apparatus is dissociated into small cytoplasmic vesicles. Funtionally, the Golgi apparatus affects the construction, processing, and intracellular targeting of synthetic products.

In chondrocytes, proteoglycan synthesis requires a well coordinated assembly of the protein and carbohydrate components. In rat chondrosarcoma cells, proteoglycan synthesis 
from translation to secretion is accomplished in 70-90 minutes, of which glycosaminoglycan chain elongation and sulphation in the Golgi apparatus takes about 15 minutes. ${ }^{17}$ We have earlier found that in short term loading experiments dynamic pressure appears to modulate the post-translational events of proteoglycan synthesis in articular cartilage explants. ${ }^{10}$ In this study we have investigated the effects of hydrostatic pressure on the structural organisation of the Golgi apparatus in cultured articular chondrocytes.

\section{Materials and methods}

CELL CULTURE

Primary bovine chondrocyte cultures were established from 1 to 2 year old animals (Itikka-Lihapolar, Kuopio, Finland). Articular cartilage from the patellar surface of the femur was minced into 1-2 $\mathrm{mm}^{3}$ pieces and sequentially digested by trypsin and crude collagenase (Sigma, St. Louis, MO, USA). Cells $\left(10^{6}\right)$ were plated on $35 \mathrm{~mm}$ Petri dishes and cultured in Basal Medium Eagle (BME) with $25 \mathrm{mM}$ Hepes and Hanks's salts (Gibco Ltd, Paisley, United Kingdom) supplemented with $10 \%$ fetal calf serum (Gibco), $3 \mathrm{mM}$ glutamine (Gibco), antibiotics $(100 \mathrm{U} / \mathrm{ml}$ penicillin and $100 \mu \mathrm{g} / \mathrm{ml}$ streptomycin, 2.5 $\mu \mathrm{g} / \mathrm{ml}$ amphotericin B) (Flow Laboratories, Irvine, United Kingdom) at $37^{\circ} \mathrm{C}$. For immunostaining and electron microscopy, glass (diameter $13 \mathrm{~mm}$ ) and plastic coverslips (Thermanox, Nunc Inc, Naperville, IL, USA) were used respectively. The medium was changed every second day.

\section{COVERING METHOD AND THE LOADING \\ APPARATUS}

After the cells reached confluence the dishes were filled by medium and sealed by a covering of Surlyn 1801-Bynel CXA 3048 bilayer membrane (thickness $90 \mu \mathrm{m}$; Du Pont, Wilmington, DE, USA) after excluding all air. The membrane was attached to the rim of the Petri dish with Jet Melt 3764 adhesive (3M United Kingdom plc, Bracknell, United Kingdom).

The loading apparatus is described in detail elsewhere. ${ }^{18}$ Briefly, the apparatus consists of two water filled cylindrical chambers one of which serves as the control, non-pressurised reference chamber and the other as the pressure chamber. During the experiments the dishes were immersed in the prewarmed $\left(37^{\circ} \mathrm{C}\right)$ distilled water. The pressure developed in the test chamber could be selected between 4 and $32 \mathrm{MPa}$. The loading and unloading periods in the cyclic pressure mode were freely selectable.

\section{LOADING PROCEDURES}

The chondrocytes on glass coverslips for immunostaining were exposed to 5,15 , or 30 $\mathrm{MPa}$ hydrostatic pressure with three cycle alternatives. In the first, the cells were exposed to continuous pressure during the whole experiment - that is, for two hours. The other loading procedures were cyclic: four seconds pressure on, followed by four seconds no pressure $(0 \cdot 125 \mathrm{~Hz})$, or one second pressure on then 19 seconds no pressure $(0.05 \mathrm{~Hz})$ for a two hour period.

To study proteoglycan synthesis, dishes without the coverslips were filled by medium and covered by the membrane as described earlier. The chondrocyte cultures were labelled with $5 \mu \mathrm{Ci} / \mathrm{ml}$ sulphur-35 labelled sulphate (carrier free, Amersham International, Little Chalfont, United Kingdom) injected through the membrane. The membrane was patched by a small piece of tape and parallel dishes were immediately incubated at $37^{\circ} \mathrm{C}$ in the pressure and reference chambers. The cultures (seven in each chamber) were pressurised continuously at $30 \mathrm{MPa}$ for two hours. After loading the dishes were put on ice and the incorporated sulphur-35 radioactivity was isolated by PD-10 columns (Sephadex G-25, Pharmacia, Sweden) and measured by liquid scintillation counter (LKB, Bromma, Sweden). The DNA content of each dish was determined by the method of Kim et al. ${ }^{19}$ For every dish the sulphate incorporation was calculated as pmol/ $\mu \mathrm{g} \mathrm{DNA} / \mathrm{h}$. The results were finally expressed as values related to the control level (pressurised/control ratio).

\section{COLD TREATMENT}

After coverage with the Surlyn membrane, Petri dishes with coverslips were cooled on ice for 30 minutes. One dish was exposed to 30 $\mathrm{MPa}$ continuous load for two hours immediately after the cold treatment and the other served as a control in the reference chamber. To confirm disruption of the microtubules in cold treatment, one part of the samples was fixed immediately after treatment with methanol at $-20^{\circ} \mathrm{C}$ for five minutes. The microtubules were visualised by using the indirect immunofluorescence technique. The primary antibody was against $\alpha$ tubulin and the secondary antibody was fluorescein isothiocyanate (FITC) conjugated antimouse IgG.

\section{NOCODAZOLE TREATMENTS}

Chondrocytes on coverslips were first incubated with $10 \mu \mathrm{M}$ nocodazole (Sigma) dissolved in dimethyl sulphoxide (DMSO) for 90 minutes at $37^{\circ} \mathrm{C}$. Some of the dishes were then exposed to $30 \mathrm{MPa}$ continuous load for two hours, whereas some served as controls without pressurisation

A series of dishes (10 in each group) treated with nocodazole and controls with a similar amount of DMSO (vehicle) were labelled with $185 \mathrm{kBq} / \mathrm{ml}^{35} \mathrm{SO}_{4}$ for 20 hours to show the influence of nocodazole on proteoglycan synthesis. After labelling, the cultures were handled as described earlier.

In the third nocodazole experiment, 10 dishes were covered by membrane as described earlier and $10 \mu \mathrm{M}$ nocodazole in DMSO was injected through the membrane. In nine 
control dishes the same amount of DMSO was added. After 90 minutes of treatment, 185 $\mathrm{kBq} / \mathrm{ml}^{35} \mathrm{SO}_{4}$ was injected and the dishes were exposed to $5 \mathrm{MPa}$ load with a $0.5 \mathrm{~Hz}$ cycle for 20 hours. The membranes were patched by a small piece of tape.

STAINING OF THE GOLGI APPARATUS

The chondrocytes on coverslips were fixed with $3.5 \%$ paraformaldehyde for five minutes at room temperature. The coverslips were treated with $0 \cdot 1 \%$ Triton $\mathrm{X}-100$ in phosphate buffered saline for five minutes. The chondrocytes were allowed to react with tetramethylrhodamine isothiocyanate conjugated wheat germ agglutinin (TRITCWGA; Vector Lab. Inc., Burlingame, CA, USA) to visualise the Golgi apparatus. ${ }^{20} \mathrm{~A}$ Nikon Microphot-FXA (Nikon, Tokyo, Japan) microscope equipped with epi-illuminator and filters for TRITC was used for photography on Kodak T-MAX 400 film.

\section{ELECTRON MICROSCOPY}

Cells on plastic coverslips were fixed with $2 \%$ glutaraldehyde in $0.1 \mathrm{M}$ sodium cacodylate ( $\mathrm{pH} 7 \cdot 4)$ at room temperature for one hour. Postfixation was performed in a mixture $(1: 1)$ of $2 \%$ glutaraldehyde in $0.1 \mathrm{M}$ cacodylate buffer, $\mathrm{pH} 7 \cdot 4$, and $1 \%$ osmium tetroxide in s-collidine buffer, $\mathrm{pH} 7 \cdot 3$, for one hour at $+4^{\circ} \mathrm{C}$. After staining with $0.5 \%$ uranyl acetate for 40 minutes, the chondrocytes were rinsed with sodium cacodylate buffer supplemented with $0.22 \mathrm{M}$ sucrose for one hour, dehydrated in a graded ethanol series and embedded in LX-112 (Ladd Research Industries, Burlington, CA, USA) as small fragments lying tangentially to the sectioning plane. Silver coloured thin sections were cut with ultramicrotome and stained with uranyl acetate and lead citrate. The sections were examined and photographed in a JEOL JEM 1200EX transmission electron microscope (JEOL Ltd, Tokyo, Japan).

\section{Results}

In these experiments the Golgi apparatus was visualised with TRITC-WGA, which specifically binds to sialic acid and $\mathrm{N}$-acetylglucosamine residues, mainly present in the Golgi apparatus after fixation and detergent permeabilisation. ${ }^{20}$ In TRITCWGA-stained chondrocytes a typical, bright, reticular, juxtanuclear staining pattern was present after paraformaldehyde fixation and Triton X-100 extraction. The Golgi apparatus formed a stacked structure polarised to one pole of the chondrocyte, leaving the other pole largely unstained (fig 1 ).

The chondrocytes were subjected to various loading procedures after reaching confluence. After continuous $30 \mathrm{MPa}$ pressure the Golgi apparatus was packed into a clump but remained in the above-mentioned region of the cell (fig 2). The morphology of some cells was also altered to a more retracted form. Under

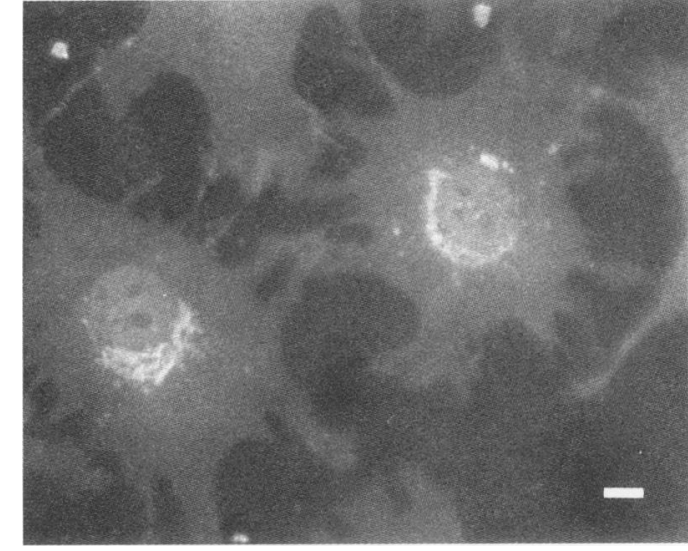

Figure 1 Chondrocytes from bovine articular cartilage cultured on coverslips, fixed with paraformaldehyde, and permeabilised with Triton $X-100$. The Golgi apparatus was stained with TRITC-WGA. The Golgi apparatus shows a typical reticular staining pattern polarising to one pole of the cell. Bar $=5 \mu \mathrm{m}$.

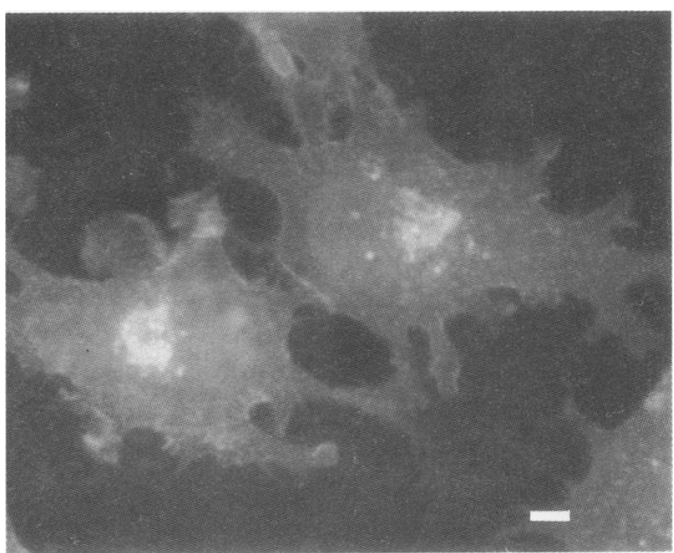

Figure 2 Articular cartilage chondrocytes as in fig 1, but exposed to $30 \mathrm{MPa}$ continuous pressure for two hours. The Golgi apparatus was packed into a clump. Bar $=5 \mu \mathrm{m}$.

electron microscopic examination control chondrocytes displayed the Golgi apparatus as a set of flattened cisternae arranged in a stack (fig 3A), but in pressurised cells the Golgi apparatus was disorganised and no stacks were found (fig 3B). Sulphate incorporation, which reflects the proteoglycan synthesis, was decreased by $18(12 \%)$ (mean (SE)) from the control values. If the $30 \mathrm{MPa}$ continuous load was extended up to 20 hours, the synthesis rate decreased by $36 \%$ (Lammi et al, unpublished data).

The reversibility of the altered structure of the Golgi apparatus was studied by fixation of coverslips $15,30,60$, and 120 minutes after withdrawing the pressure. After 15 minutes no recovery was seen, but after 60 minutes the organisation of the Golgi apparatus was fully re-established (data not shown).

If the chondrocytes were exposed to cyclic loading with $30 \mathrm{MPa}$ using $0 \cdot 125 \mathrm{~Hz}$ (fig 4) or $0.05 \mathrm{~Hz}$ loading regime for two hours, no structural change in the Golgi apparatus was. observed.

After a continuous $15 \mathrm{MPa}$ pressure the packing of the Golgi apparatus was also visible, 

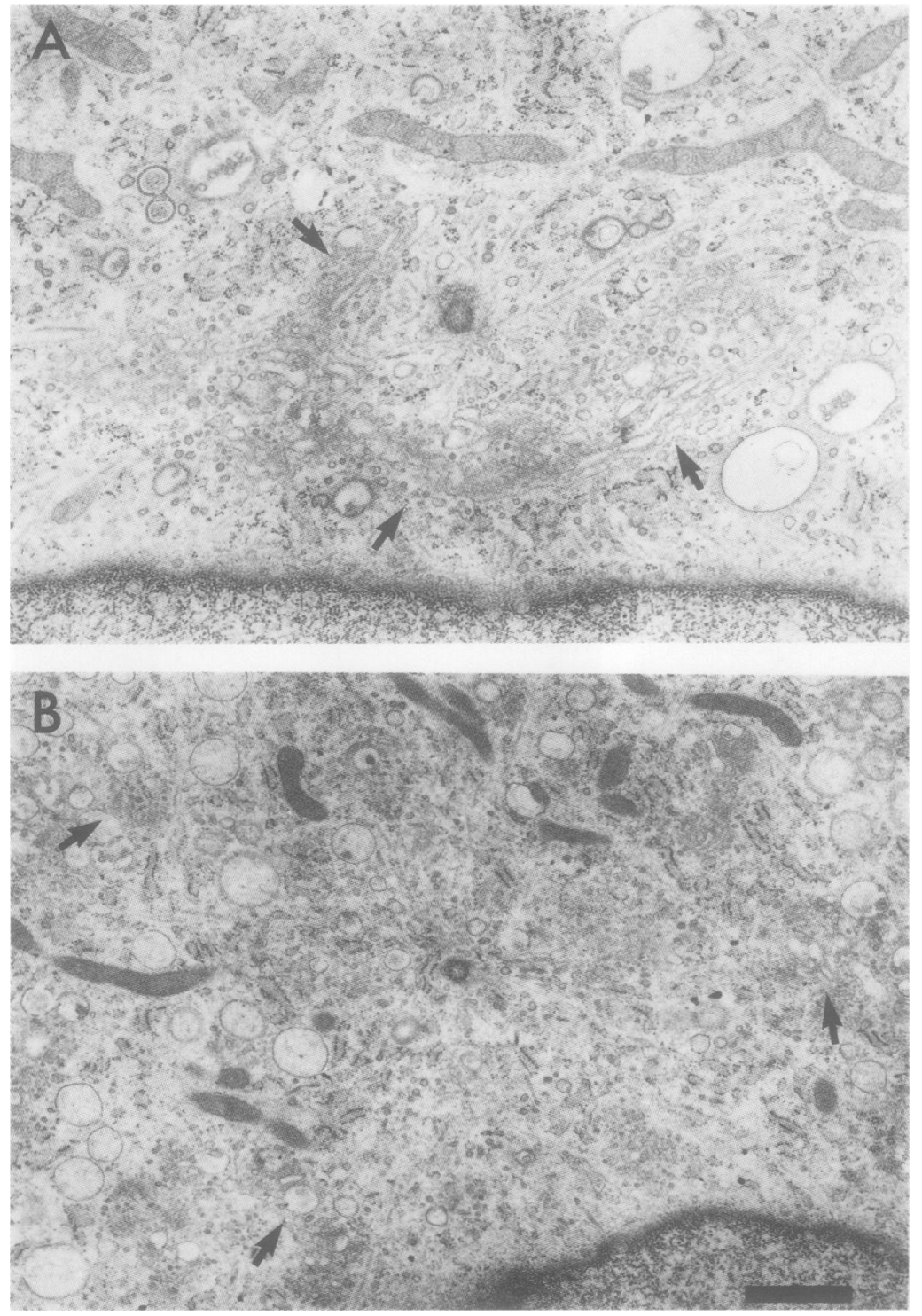

Figure 3 Transmission electron microscopy view of the perinuclear area of chondrocytes in the control culture $(A)$ and after two hours continuous loading under $30 \mathrm{MPa}$ pressure $(B)$. The cells were fixed in $2 \%$ glutaraldehyde, postfixed in a mixture of glutaraldehyde and osmium tetroxide, and embedded in LX-112 resin. The sections were stained with uranyl acetate and lead citrate. In control chondrocytes $(A)$ the Golgi apparatus (arrows) was organised in stacks near the centriole but in the pressurised cells numerous vesicles (arrows) of various sizes were visible in the same region and no stacks of cisternae were visible (B). $B a r=1 \mu m$. but not as striking and not in every cell as after $30 \mathrm{MPa}$ (fig 5). These morphological alterations did not appear when $15 \mathrm{MPa}$ cyclic pressure $(0.125 \mathrm{~Hz}, 0.05 \mathrm{~Hz})$ was used. The structure of the Golgi apparatus showed no gross alterations after $5 \mathrm{MPa}$ continuous pressure (fig 6).

The microtubules in chondrocytes were disrupted after half an hour of cold treatment (fig 7A). The typical radial staining pattern of the microtubules seen in control cells (data not shown) was absent following cold treatment. The morphology of the Golgi apparatus remained intact through this treatment (fig 7B), however, and during the subsequent rearrangement period of the microtubules at $37^{\circ} \mathrm{C}$ (fig 7C). Pressurisation at $30 \mathrm{MPa}$ immediately after cold treatment led to clumping of the Golgi apparatus into the perinuclear area as seen without cold treatment (fig 7D).

Nocodazole, which reversibly and highly specifically disrupts the microtubules, led to fragmentation and dispersion of the Golgi apparatus over the cytoplasm (fig 8A). After pressurisation of the nocodazole treated chondrocytes, the Golgi apparatus remained

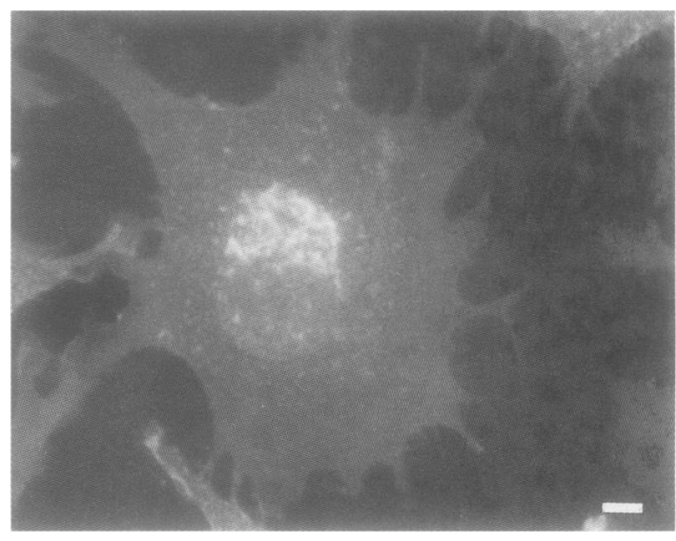

Figure 5 Chondrocytes as in fig 1 but exposed to $15 \mathrm{MPa}$ continuous pressure for two hours. Cell morphology is similar to control cultures but the Golgi apparatus is condensed to form a packed structure. Bar $=5 \mu \mathrm{m}$.

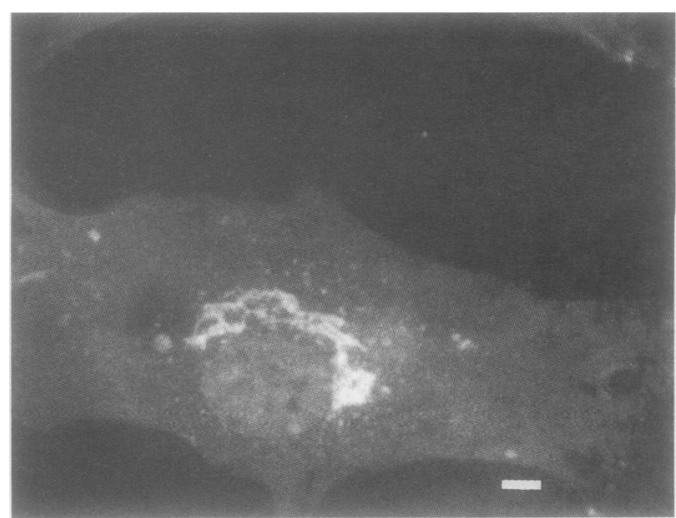

Figure 6 Chondrocytes exposed to $5 \mathrm{MPa}$ continuous hydrostatic pressure for two hours. The Golgi apparatus represents the normal staining pattern in cultured chondrocytes as in fig 1. Bar $=5 \mu \mathrm{m}$.
Figure 4 Chondrocytes exposed to $30 \mathrm{MPa}$ cyclic $(0 \cdot 125 \mathrm{~Hz})$ pressure for two hours. No alterations in the morphology of the cell or the Golgi apparatus compared with fig 1. Bar $=5 \mu \mathrm{m}$. 

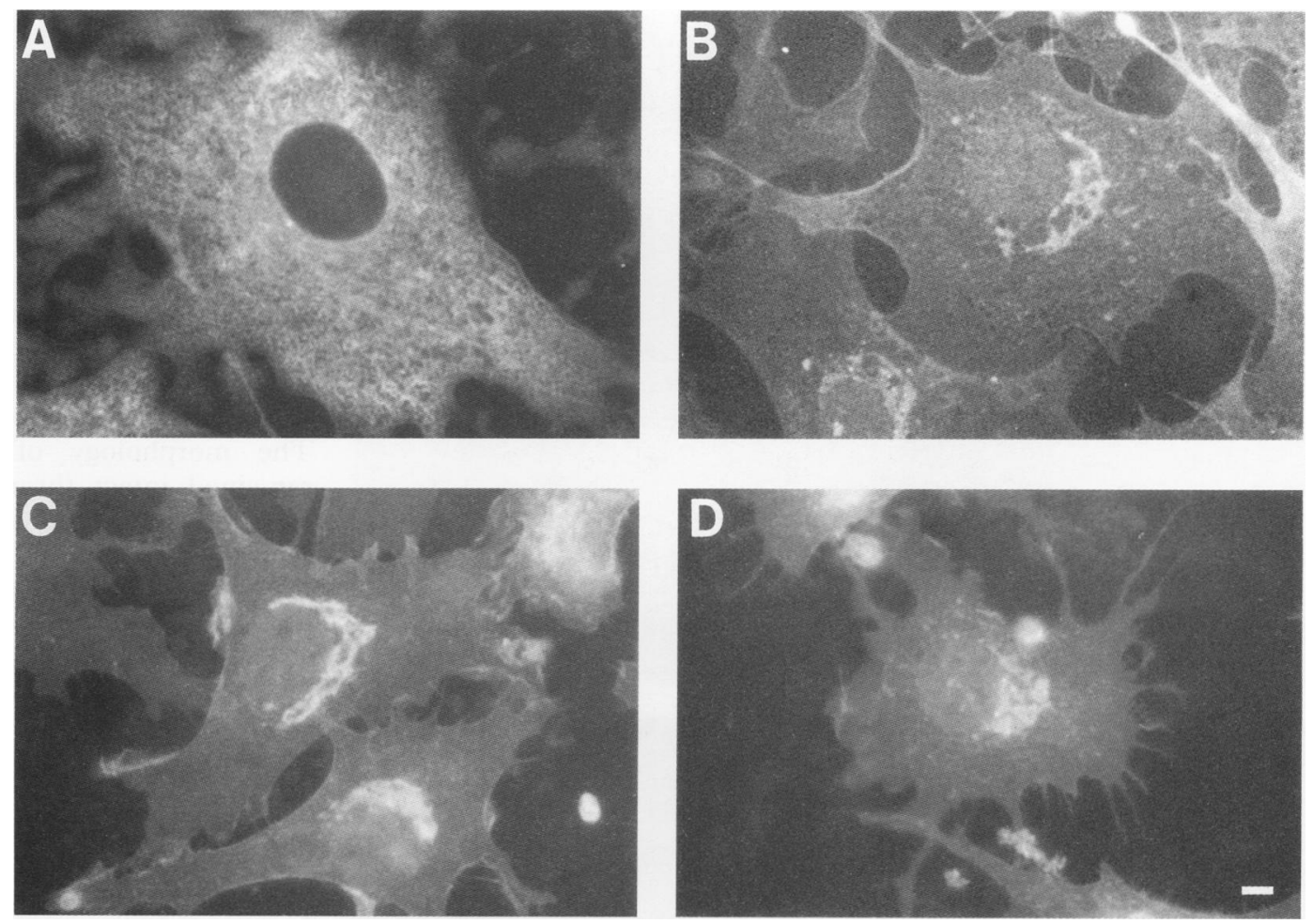

Figure 7 Chondrocytes kept at $0^{\circ} \mathrm{C}$ for 30 minutes before pressurisation. The cold treatment leads to disruption of microtubules $(A)$, but the Golgi apparatus is located juxtanuclearly with the typical staining pattern. There were no alterations in the morphology of the cells $(B)$. After cold treatment the cells were placed to $37^{\circ} \mathrm{C}$ for two hours $(C)$. The staining pattern of the Golgi apparatus remains as in fig $7 \mathrm{~B}$. In continuously pressurised chondrocytes after $30 \mathrm{MPa}$ pressure for two hours at $37^{\circ} \mathrm{C}$ the Golgi apparatus is clumped into the perinuclear area (D) as without cold treatment (fig 2). Bar $=5 \mu \mathrm{m}$.
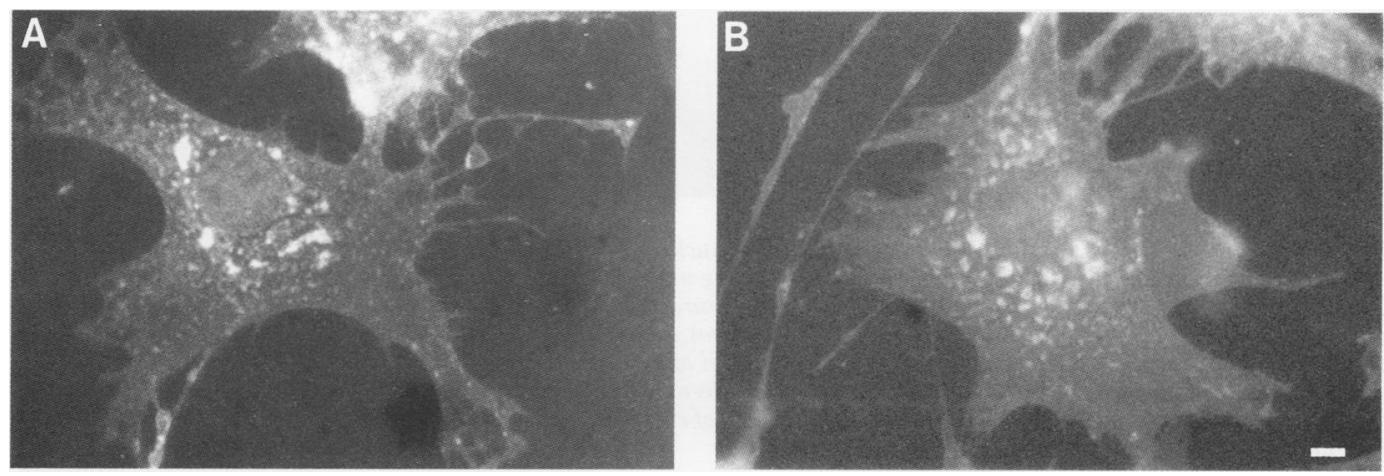

Figure 8 Chondrocytes cultured in the presence of microtubule disrupting agent (10 $\mu \mathrm{M}$ nocodazole for 90 minutes), which led to the fragmentation and dispersion of the Golgi apparatus over the cytoplasm $(A)$, and after pressurisation in $30 \mathrm{MPa}$ continuous load (B). There is no packing of the Golgi apparatus in the absence of microtubules. Bar $=5 \mu \mathrm{m}$.

dispersed in the cytoplasm and loading had no effect on its vesicular appearance (fig $8 \mathrm{~B}$ ). The morphology of the chondrocytes remained unchanged during nocodazole treatment. Nocodazole had a drastic influence on proteoglycan synthesis, which decreased to $50(2) \%$ of the control values. Nocodazole treatment also blocked the effect of a $5 \mathrm{MPa}$, $0.5 \mathrm{~Hz}$ loading regimen, which was shown to stimulate proteoglycan synthesis without nocodazole. ${ }^{18}$

\section{Discussion}

The Golgi apparatus plays an important part in the processing and sorting of secretory proteins. ${ }^{15}$ It is particularly essential in cells such as chondrocytes, the main function of which is to synthesise and export macromolecules for the maintenance of the extracellular matrix. In chondrocytes the glycosylation and sulphation of proteoglycans take place in the Golgi apparatus, where specific enzymes sequentially add more than 1000 sugar residues into the chondroitin sulphate and keratan sulphate chains of a single large cartilage proteoglycan molecule (aggrecan). In this study we have shown that hydrostatic pressure altered the structure of the Golgi apparatus, which may account for the previously observed decrease in proteoglycan synthesis. $^{21}$

Sialic acid, the terminal residue of several oligosaccharides including cartilage keratan 
sulphate, is attached to its substrates by the Golgi apparatus sialyl transferases. Therefore WGA, which binds to sialic acid residues, can be used for staining the Golgi apparatus. TRITC-WGA binding sites are localised in the medial and trans cisternae of the Golgi apparatus. ${ }^{22}$ In TRITC-WGA stained cells the Golgi apparatus was clumped juxtanuclearly after continuous $30 \mathrm{MPa}$ pressure. Electron microscopy after this loading procedure revealed that the clumping of the Golgi apparatus resulted from the disorganisation of the Golgi stacks. The Golgi apparatus was probably fragmented and condensed into the juxtanuclear cytoplasm and wads visualised as a clumped structure by light microscopy.

The stresses acting in the bovine knee joint have not been measured, but it has been estimated that the static compressive stress in the knee joints of cows is $0.8 \mathrm{MPa} .^{23}$ The stresses on the cartilage surface in various species of different sizes, including humans, are relatively constant. During the walking cycle, $0 \cdot 8-6 \cdot 3 \mathrm{MPa}$ pressures can be found in the human knee joint, ${ }^{24}$ but in the human hip joint peak pressures exceeding $18 \mathrm{MPa}$ have been measured..$^{25}$ Therefore, $5 \mathrm{MPa}$ appears to represent an ordinary physiological pressure level, $15 \mathrm{MPa}$ a high physiological pressure, whereas $30 \mathrm{MPa}$ is possibly beyond the physiological pressure range.

Thus far little is known of the mechanism by which the pressure influences the chondrocytes. We have suggested that hydrostatic pressure is one of the main components controlling proteoglycan synthesis rates in articular cartilage. ${ }^{10}$ The applied hydrostatic pressures have been small in many previous experiments compared with physiological pressure levels in joints. ${ }^{26}$ Our results with $30 \mathrm{MPa}$ agree, however, with the findings of Hall and Urban $^{21}$ that high continuous hydrostatic pressure (two hours, 50 $\mathrm{MPa}$ ) inhibits sulphate incorporation. The cited study also indicated that the general protein synthesis in chondrocytes, measured as proline incorporation, decreased due to the continuous high hydrostatic pressure. With 5 $\mathrm{MPa}$ we found no changes in the structure of the Golgi apparatus. A cyclic hydrostatic pressure of $5 \mathrm{MPa}$, however, influences proteoglycan synthesis, ${ }^{18}$ suggesting that hydrostatic pressure can modulate proteoglycan synthesis without changes in the gross organisation of the Golgi apparatus.

The polygonal morphology of the cells, maintained by the actin filaments and the microtubules, is typical of cultured chondrocytes. ${ }^{27}$ The general morphology of the chondrocytes was not affected by depolymerisation of the microtubules with nocodazole, indicating that the microtubules had no direct effect on the cell shape. ${ }^{28}{ }^{29}$ After pressurisation, however, the shape of some cells was altered to a retracted form, possibly due to disruption of the stress fibres. ${ }^{28}$ These findings suggest that the disruption of cell to cell and cell to substrate adhesions was responsible for the alterations of the general cell morphology. ${ }^{28}$ Our results agree with the earlier findings that a certain pressure level must be exceeded to achieve a change in cell morphology. ${ }^{28}$

The alterations of the Golgi apparatus depended on the pressure level and the cycle applied. Within the range of physiological pressures (15 MPa or less) some packing occurred in the Golgi apparatus but no changes were observed in the general cell morphology. This suggests that the change in the Golgi apparatus is one of the first structural alterations following an increase in hydrostatic pressure and not due to the general impact of pressure on the cell shape.

The morphology of the Golgi apparatus is closely associated with the integrity of the microtubules, ${ }^{30}$ possibly through microtubule associated proteins. ${ }^{31}$ The role of the microtubules in the packing of the Golgi apparatus was tested by exposing the chondrocytes to 30 $\mathrm{MPa}$ pressure after depolymerising the microtubules. This was accomplished by nocodazole, which binds tubulin heterodimers and inhibits their polymerisation, resulting in progressive depolymerisation of the microtubules. The treatment led to fragmentation of the Golgi apparatus into numerous vesicles scattered throughout the cytoplasm. High hydrostatic pressure did not induce clumping of the Golgi apparatus in these cells, suggesting that intact microtubules were essential for the packing of the Golgi apparatus on increased hydrostatic pressure. Proteoclycan synthesis was reduced to half of the control level due to the depolymerisation of the microtubules and packing of the Golgi apparatus. As proteoglycan secretion still proceeded, though at a reduced rate, it seems that there must be routes independent of microtubules to transport newly synthesised proteoglycans to plasma membrane. The microtubules are possibly essential in gathering the Golgi cisternae into a single stack. ${ }^{15}$ The role of the microtubules in the secretion of proteoglycans is then more facilitatory than obligatory. The individual Golgi cisternae or vesicles may operate independently but not as efficiently as the whole Golgi apparatus. $^{32} 33$

After depolymerisation of the microtubules, hydrostatic pressure had no effect on sulphate incorporation with the stimulatory loading regime. ${ }^{18}$ Therefore, without microtubules, the chondrocytes could not respond to the hydrostatic pressure or, alternatively, the capacity of even slightly dispersed stacks was insufficient for the stimulatory response.

The situation after the cold treatment was different. The microtubules are depolymerised at low temperatures ${ }^{34}{ }^{35}$ but there was no fragmentation or dispersion of the Golgi apparatus. This was probably due to lowered metabolism in the cold, ${ }^{33}$ and may also indicate that the structural change in the Golgi apparatus is dependent on a continuous supply of energy. When the cold treated cells were placed at $37^{\circ} \mathrm{C}$ and immediately pressurised the Golgi apparatus changed into the packed form.

This is the first report of the influence of hydrostatic pressure on the Golgi apparatus organisation in eukaryotic cells. These results 
suggest that in chondrocytes the hydrostatic pressure modifies the structure of the Golgi apparatus. The gross alterations of the Golgi apparatus occur at high pressure levels, but still within the range measured in cartilage in vivo. ${ }^{25}$ Cartilage proteoglycan synthesis is also inhibited by the high hydrostatic pressure ${ }^{9}$ (Lammi et al, unpublished data). Although the comparison of the in vivo and in vitro experiments is complicated, the pressure response can be induced in the chondrocytes and the cartilage explants. The matrix of cartilage probably modulates the response to loading. Cultured chondrocytes can be used, however, to study the mechanisms by which pressure effects are mediated in the cells. Although no changes in the Golgi apparatus were seen with low pressures, it is still possible that low pressures influence the Golgi apparatus without changes in the gross appearance of the organelle. These data thus indicate that high hydrostatic pressure causes structural changes in the Golgi apparatus which may affect the decreased processing rate of proteoglycans in the chondrocytes.

This work was supported by grants from The North Savo Fund of the Finnish Cultural Foundation, the Research and Science Foundation of Farmos, the Paulo Foundation, the Academy of Finland and the Finnish Research Council for Physical Education and Sports, Ministry of Education. The authors give their compliments to Mrs Eija Rahunen, Mrs Elma Sorsa Mrs Eija Voutilainen, and Ms Eija Antikainen for their skilful technical assistance.

1 Tammi M, Paukkonen K, Kiviranta I, Jurvelin J, Säämänen A-M, Helminen $\mathrm{H}$ J. Joint loading induced alterations in articular cartilage. In: Helminen H J, Kiviranta I, Säämänen A-M, Tammi M, Paukkonen K, Jurvelin J, eds. Foint loading. Biology and health of articular structures. Bristol: Wright, 1987: 64-68.

2 Kiviranta I, Tammi $M$, Jurvelin J, Säämänen A-M, Helminen H J. Moderate running exercise augments glycosaminoglycans and thickness of articular cartilage in the knee joint of young beagle dogs. F Orthop Res 1988; 6: 188-95.

3 Säämänen A-M, Tammi M, Kiviranta I, Jurvelin J, Helminen $\mathrm{H} \mathrm{J}$. Levels of chondroitin-6-sulfate and nonaggregating proteoglycans at articular cartilage contact sites in the knees of young dogs subjected to moderate running exercise. Arthritis Rheum 1989; 32: 1282-92.

4 Kiviranta I, Tammi M, Jurvelin J, Arokoski J, Säämänen A-M, Helminen $\mathrm{H} \mathrm{J}$. Articular cartilage thickness and glycosaminoglycan distribution in the canine knee joint after strenuous ( $20 \mathrm{~km} /$ day) running exercise. Clin Orthop 1992; 283: 302-8.

5 Kiviranta I, Jurvelin J, Tammi M, Säämänen A-M, Helminen $\mathrm{H}$ J. Weight-bearing controls glycosaminoglycan concentration and thickness of articular cartilage in the knee joint of young beagle dogs. Arthritis Rheum 1987; 80: 901-8.

6 Säämänen A-M, Tammi M, Jurvelin J, Kiviranta I, Helminen $\mathrm{H}$ J. Proteoglycan alterations following immobilization and remobilization in the articular cartilage of young canine knee (stifle) joint. F Orthop Res 1990; 8: 863-73.

7 Jurvelin J, Kiviranta I, Arokoski J, Tammi M, Helminen H $\mathrm{J}$. Indentation study of the biomechanical properties of articular cartilage in the canine knee. Eng Med 1987; 16: articular

8 Jannasch H W, Marquis R E, Zimmerman A M. Current perspectives in high pressure biology. London: Academic Press, 1987

9 Hall A C, Urban J P G, Gehl K A. The effects of hydrostatic pressure on matrix synthesis in articular cartilage. $\mathcal{F}$ Orthop Res 1991; 9: 1-10.

10 Parkkinen J J, Lammi M J, Helminen H J, Tammi M. Local stimulation of proteoglycan synthesis in articular cartilage explants by dynamic compression in vitro. $\mathcal{F}$. Orthop Res 1992; 10: 610-20.

11 Goldinger J M, Kang B S, Choo Y E, Paganelli C V, Hong $\mathrm{S} \mathrm{K}$. Effect of hydrostatic pressure on ion transport and metabolism in human erythrocytes. F. Appl Physiol 1980 49: $224-31$

12 Heinemann S H, Conti, F, Stuhmer W, Neher E. Effects of hydrostatic pressure on membrane processes. $\mathcal{F} \mathrm{Gen}$ Physiol 1989; 90: 765-78.

13 Landau J V. Hydrostatic pressure on the biosynthesis of macromolecules. In: Zimmerman A M, ed. High pressure effects on cellutar

14 Dibb W, Morild E, Laerum O D. Effects of high hydrostatic pressure on normal and neoplastic rat cells in culture. Virch Archiv [B] 1981; 38: 169-76.

15 Thyberg J, Moskalewski S. Microtubules and the organization of the Golgi complex. Exp Cell Res 1985; 159: $1-16$.

16 Lohmander S, Moskalewski S, Madsen K, Thyberg J, Friberg U. Influence of colchicine on the synthesis and secretion of proteoglycans and collgen by fetal guinea pig secretion of proteoglycans and collgen by fetal

17 Mitchell D, Hardingham T. The effects of cycloheximide on the biosynthesis and secretion of proteoglycans by chondrocytes in culture. Biochem $71981 ; 196$ : $521-9$.

18 Parkkinen J J, Ikonen J, Lammi M J, Laakkonen J, Tammi $\mathrm{M}$, Helminen $\mathrm{H} \mathrm{J}$. Effects of hydrostatic pressure on proteoglycan synthesis in cultured chondrocytes and articular cartilage explants. Arch Biochem Biophys. In press.

19 Kim Y-J, Sah R L Y, Doong J-Y H, Grodzinsky A J. Fluorometric assay of DNA in cartilage explants using Hoechst 33258. Anal Biochem 1988; 174: 168-76.

20 Virtanen I, Ekblom P, Laurila P. Subcellular compartmentalization of saccharide moieties in cultured compartmentalization of saccharide moieties in cultured

21 Hall A C, Urban J P G. Responses of articular chondrocytes and cartilage to high hydrostatic pressure. Trans Ortho Res Soc 1989; 14: 49.

22 Velasco A, Hidalco J. Müller M, Garcia-Herdugo G. Ultrastructural demonstration of lectin binding sites in the golgi apparatus of rat epiphyseal chondrocytes. Histochemistry 1988; 89: 177-84.

23 Simon W H. Scale effects in animal joints I. Articular cartilage thickness and compressive stress. Arthritis Rheum 1970; 13: 244-56.

24 Finlay J B, Repo R U. Instrumentation and procedure for the controlled impact of articular cartilage. IEEE Trans Biomed Eng 1978; 25: 34-9.

25 Hodge W A, Fijan R S, Carlson K L, Burgess R G, Harris W $H$, Mann $R$ W. Contact pressures in the human hip joint measured in vivo. Proc Natl Acad Sci USA 1986; 83: 2879-83.

26 Kampen van G P J, Stadt van de R J. Cartilage and chondrocyte responses to mechanical loading in vitro. In; Helminen H J, Kiviranta I, Säämänen A-M, Tammi $M$, Paukkonen K, Jurvelin J, eds. Foint loading. Biology and health of articular structures. Bristol: Wright, 1987: $112-25$.

27 Adolphe $M$. Articular chondrocytes in culture: applications in pharmacology. Advances in Cell Culture 1987; 5 $19-42$.

28 Bourns B, Franklin S, Cassimeris L, Salmon E D. High hydrostatic pressure effects in vivo: changes in cell morphology, microtubule assembly, and actin organization. Cell Motil Cytoskeleton 1988; 10: 380-90.

29 Vasiliev J M, Gelfand I M. Effects of colcemid on morphogenic processes and locomotion of fibroblasts. In: Goldman T, Pollard T D, Rosenbaum J, eds. Cell Motility. Cold Spring Harbor, NY: Cold Spring Harbor Laboratories, $1976 ; 279-304$.

30 Katsumoto $T$, Inoue $M$, Naguro $T$ Kurimura $T$. Association of cytoskeleton with the Golgi apparatus: Association of cytoskeleton with the Golgi apparatus: three-dimensional observation and computer-
reconstruction. $\mathcal{f}$ Electron Microsc 1991; 40: 24-8.

31 Allan V J, Kreis T E. A microtubule-binding protein associated with membranes of the golgi apparatus. $\mathcal{F}$ Cell Biol 1986; 103: 2229-39.

32 Madsen K, Holmström S, Ostrowski K. Synthesis and secretion of proteoglycans by cultured chondrocytes. Effects of monensin, colchicine and B-D-Xyloside. Exp Cell Res 1983; 148: 493-501.

33 Turner J R, Tartakoff A M. The response of the golg complex to microtubule alterations: the roles of metabolic energy and membrane traffic in golgi complex energy and membrane traffic in golgi

34 Moskalewski S, Thyberg J, Friberg U. Cold and metabolic effects on cytoplasmic microtubules and Golgi complex in cultured rat epiphyseal chondrocytes. Cell Tissue Res 1980; 210: 403-15.

35 Virtanen I, Lehto V-P, Lehtonen E, Badley R A Organization of intermediate filaments in culture fibroblasts upon disruption of microtubules by cold treatment. Eur f Cell Biol 1980; 23: 80-4. 